medRxiv preprint doi: https://doi.org/10.1101/2021.09.21.21263845; this version posted September 26, 2021. The copyright holder for this preprint (which was not certified by peer review) is the author/funder, who has granted medRxiv a license to display the preprint in perpetuity.

All rights reserved. No reuse allowed without permission.

\title{
Evidence of Persisting Autoreactivity in Post-Acute Sequelae of SARS-CoV-2 Infection
}

\section{Authors:}

Matthew C. Woodruff', ${ }^{1,}$ Tiffany A. Walker ${ }^{3}$, Alexander D. Truong ${ }^{4}$, Adviteeya N. Dixit ${ }^{4}$, Jenny E. Han ${ }^{4}$, Richard P. Ramonell ${ }^{4}$, Martin C. Runnstrom ${ }^{4}$, Mark E. Rudolph ${ }^{5}$, Arezou Khosroshahi ${ }^{1,2}$, F. Eun-Hyung Lee ${ }^{3^{*}}$, Ignacio $\operatorname{Sanz} z^{1,2^{*}}$

\section{Affiliations:}

${ }^{1}$ Department of Medicine, Division of Rheumatology, Lowance Center for Human Immunology, Emory University, Atlanta, GA, USA

${ }^{2}$ Emory Autoimmunity Center of Excellence, Emory University, Atlanta, GA, USA

${ }^{3}$ Department of Medicine, Division of General Internal Medicine, Emory University, Atlanta, GA, USA

${ }^{4}$ Department of Medicine, Division of Pulmonary, Allergy, Critical Care and Sleep Medicine, Emory University, Atlanta, GA, USA

${ }^{5}$ Exagen Inc., Vista, CA, USA

${ }^{*}$ Corresponding authors: Drs. F. Eun-Hyung Lee and Ignacio Sanz

\section{Abstract:}

Recent studies have demonstrated significant breadth of emerging autoreactivity in severe SARS-CoV-2 infection. Importantly, we have identified a relaxation of peripheral tolerance within early antibody secreting cells that emerge in patients with COVID-19 as important drivers of those responses. While often viral-specific, these extrafollicular-derived cells also display cross reactivity to autoantigens present in the inflammatory lung environment, and despite resolution of most autoreactivity within 6 months, they persisted in some patients. These results raise questions regarding autoreactive antibodies that arise during acute SARS-CoV-2 infection and their persistence in patients with symptoms in Post-Acute Sequelae of SARS-CoV-2 infection (PASC). Through clinical autoreactive antibody screening of 95 patients with PASC and no history of autoimmune disease, we identify significant autoreactive profiles in patients with ongoing symptoms post-recovery, with $80 \%$ of patients returning positive tests for at least one autoantigen, and $40 \%$ showing breaks in tolerance to 2 or more. Anti-nuclear antigen positivity was most common, displaying positivity in $63 \%$ of patients, however, positive tests were broad and included reactivities against carbamylated protein responses, RNA polymerase III, and phospholipids. We also identify patients with reactivity against dsDNA in the PASC cohort - a reactivity not observed in acute infection even in the critically ill. These results demonstrate evidence of elevated serum autoantibodies in patients who present to PASC clinics with persistent symptoms up 14 months following SARS-CoV-2 infection, and further confirm the growing linkage between COVID-19 and observed clinical autoreactivity - even into the recovery phase of disease. 
medRxiv preprint doi: https://doi.org/10.1101/2021.09.21.21263845; this version posted September 26, 2021. The copyright holder for this preprint (which was not certified by peer review) is the author/funder, who has granted medRxiv a license to display the preprint in perpetuity.

All rights reserved. No reuse allowed without permission.

\section{Main Text}

Recent studies have demonstrated the significant breadth of emerging autoreactivity in severe SARS-CoV-2 infection $^{1-3}$. More specifically, we have identified a relaxation of peripheral tolerance within early antibody secreting cells that emerge in patients with COVID-19 as important drivers of those responses ${ }^{2}$. While often viral-specific, these extrafollicular-derived cells ${ }^{4}$ also display cross reactivity to autoantigens present in the inflammatory lung environment including glomerular basement membrane and naïve $B$ cell reactivity. Antinuclear antibodies (ANA) and anti-carbamylated protein (CarP) responses were highly represented $(42 \%$ and $44 \%$, respectively), and despite resolution of most autoreactivity within 6 months, they persisted in some patients ${ }^{2}$. These results raise questions regarding autoreactive antibodies that arise during acute SARS-CoV-2 infection and their persistence in patients with symptoms in Post-Acute Sequelae of SARS-CoV-2 infection $(\mathrm{PASC})^{5,6}$.

To explore the possibility that autoreactivity is over-represented in patients diagnosed with PASC, 95 patients with heterogeneous symptomology were consecutively recruited upon presentation to two academic PASC clinics in Atlanta, Georgia, USA during December 2020-June 2021. Enrollees had a median age of 50 years (range 21-81), 72 (76\%) were female, and the majority were African American (58\%) (Table 1). Fifty-five $(58 \%)$ had mild acute COVID-19 with the remaining requiring hospitalization. At the time of sampling, patients were a median of 110 days (range 22-446) from COVID-19 onset, with the most common self-reported PASC symptoms included dyspnea (69\%), fatigue (64\%), and brain fog (47\%) (Table 1). Patients who were suspected or diagnosed with rheumatic diseases prior to COVID-19 diagnosis were excluded from the cohort.

The ninety-five participants consenting to enrollment had a median age of 50 years (range 21-81), 72 (76\%) were female, and the majority were African American (58\%) (Table 1). Fifty-five (58\%) had mild acute COVID19 with the remaining requiring hospitalization. At the time of sampling, patients were a median of 110 days (range 22-446) from COVID-19 onset, with the most common self-reported PASC symptoms included dyspnea $(69 \%)$, fatigue $(64 \%)$, and brain fog $(47 \%)$ (Table 1). Patients who were suspected or diagnosed with rheumatic diseases prior to COVID-19 diagnosis were excluded from the cohort.

Similar to the patients hospitalized with COVID-19, $80 \%$ of PASC patients tested positive for reactivity against at least one autoantigen, with elevated ANAs (63\%) particularly prominent in the cohort. (Fig 1a). Anti-CarP responses alongside reactivity against RNA polymerase 3 were also elevated with $16 \%$ and $8 \%$ of patients returning positive tests, respectively (Fig 1a,b). Of interest, dsDNA was uniquely elevated in the PASC cohort, with 3 patients (3\%) returning positive clinical tests and an additional 4 (7\%, total) expressing titers exceeding 5 standard deviations of a matched healthy donor cohort (Fig 1a,c). Multiple breaks in tolerance were common with more than a third of patients $(40 \%)$ displaying tolerance breaks against 2 or more independent autoantigens (Fig 1d).

In summary, these results demonstrate evidence of elevated serum autoantibodies in patients who present to PASC clinics with persistent symptoms up 14 months following SARS-CoV-2 infection. Whether these autoantibodies in patients early post-recovery with PASC correlate with long-term persistence of symptoms and eventual diagnosis of autoimmune disease will require further study. Nonetheless, these data further confirm the growing linkage between COVID-19 and observed clinical autoreactivity - even into the recovery phase of disease. Further, the identification of persistent autoreactive antibodies, identifiable through formal rheumatologic evaluation, should be routinely considered as possible contributing factors in the development and persistence of post-acute sequelae following COVID-19 recovery.

\section{References}

1. Wang EY, Mao T, Klein J, et al. Diverse functional autoantibodies in patients with COVID-19. Nature 2021. DOI: $10.1038 / s 41586-021-03631-y$.

2. Woodruff MC, Ramonell RP, Saini AS, et al. Relaxed peripheral tolerance drives broad de novo autoreactivity in severe COVID-19. medRxiv 2021. DOI: 10.1101/2020.10.21.20216192.

3. Chang SE, Feng A, Meng W, et al. New-onset IgG autoantibodies in hospitalized patients with COVID19. Nat Commun 2021;12(1):5417. DOI: 10.1038/s41467-021-25509-3. 
medRxiv preprint doi: https://doi.org/10.1101/2021.09.21.21263845; this version posted September 26, 2021. The copyright holder for this preprint (which was not certified by peer review) is the author/funder, who has granted medRxiv a license to display the preprint in perpetuity. All rights reserved. No reuse allowed without permission.

4. Woodruff MC, Ramonell RP, Nguyen DC, et al. Extrafollicular B cell responses correlate with neutralizing antibodies and morbidity in COVID-19. Nat Immunol 2020;21(12):1506-1516. DOI: 10.1038/s41590-020-00814-z.

5. Nalbandian A, Sehgal K, Gupta A, et al. Post-acute COVID-19 syndrome. Nat Med 2021;27(4):601-615. DOI: 10.1038/s41591-021-01283-z.

6. Al-Aly Z, Xie Y, Bowe B. High-dimensional characterization of post-acute sequelae of COVID-19. Nature 2021;594(7862):259-264. DOI: 10.1038/s41586-021-03553-9.

\section{Methods}

\section{Human Participants}

All research was approved by the Emory University Institutional Review Board (Emory IRB nos. IRB00058507, IRB00057983 and IRB00058271) and was performed in accordance with all relevant guidelines and regulations. Informed consent was obtained from all participants or, if they were unable to provide informed consent, from designated healthcare surrogates. Healthy individuals $(n=14)$ were recruited using promotional materials approved by the Emory University Institutional Review Board.

\section{Acute COVID-19 Participants}

Individuals with acute COVID-19 $(n=44)$ were recruited from Emory University Hospital, Emory University Hospital Midtown and Emory St. Joseph's Hospital (all Atlanta, USA). Participants aged $\geq 18$ years with documented PCR amplification of SARS-CoV-2 viral RNA obtained from nasopharyngeal or oropharyngeal swabs who were not immunocompromised and had not received oral or intravenous corticosteroids within the preceding $14 \mathrm{~d}$ were eligible.

\section{PASC Participants}

Patients with PASC $(n=95)$ were referred by primary care providers or by self-referral to Emory University Midtown, Emory University Executive Park, and Grady Memorial Hospital PASC Clinics. Adults aged $\geq 18$ years with documented SARS-CoV-2 antigen or anti-nucleocapsid antibody (64\%), or those meeting the CDC COVID-19 clinical case definition who were experiencing new or worsening symptoms and were $>14$ days from COVID-19 onset (36\%) were eligible. Sociodemographic, comorbidity, acute COVID-19, and PASC symptom data were collected by patient report through a review of systems and confirmed through medical record review.

\section{All Participants}

Peripheral blood was collected in either heparin sodium tubes (PBMCs) or serum tubes (serum; both BD Diagnostic Systems). Study data were collected and managed using REDCap electronic data capture tools hosted at Emory University.

\section{Clinical Autoreactivity Testing}

For autoimmune biomarker analysis, frozen plasma was shipped on dry ice to Exagen, Inc. (Vista, California, USA) which has a clinical laboratory accredited by the College of American Pathologists (CAP) and certified under the Clinical Laboratory Improvement Amendments (CLIA). Thawed plasma was aliquoted and distributed for the following tests: anti-nuclear antibodies (ANA) were measured using enzyme-linked immunosorbent assays (ELISA) (QUANTA Lite; Inova Diagnostics) and indirect immunofluorescence (IFA) (NOVA Lite; Inova Diagnostics); anti-double-stranded DNA (dsDNA) antibodies were also measured by ELISA and were confirmed by IFA with Crithidia luciliae; extractable nuclear antigen autoantibodies (anti-Sm, anti-SS-B/La IgG, anti-Scl-70 lgG, anti-U1RNP IgG, anti-RNP70 lgG, anti-CENP IgG, anti-Jo-1 lgG, and anti-CCP lgG) as well as Rheumatoid Factor (RF) IgA and IgM were measured using the EliA test on the Phadia 250 platform (ThermoFisher Scientific); IgG, IgM, and IgA isotypes of anti-cardiolipin and anti- $\beta 2$-glycoprotein, as well as anti-Ro52, anti-Ro60, anti-GBM, anti-PR3, and anti-MPO were measured using a chemiluminescence immunoassay (BIO-FLASH; Inova Diagnostics); anti-CarP, anti-RNA-pol-III, and the IgG and IgM isotypes of anti-PS/PT were measured by ELISA (QUANTA Lite; Inova Diagnostics), while C- and P-ANCA were measured by IFA (NOVA Lite; Inova Diagnostics). All assays were performed following the manufacturer's instructions. 
medRxiv preprint doi: https://doi.org/10.1101/2021.09.21.21263845; this version posted September 26, 2021. The copyright holder for this preprint (which was not certified by peer review) is the author/funder, who has granted medRxiv a license to display the preprint in perpetuity. All rights reserved. No reuse allowed without permission.

Figure 1 - Autoreactivity in Post-Acute Sequelae of SARS-CoV-2 Plasma from 95 patients with mixed PACS symptomology was screened by Exagen clinical laboratory for reactivity against 30 clinically-relevant autoantigens. (a) Heatmap of patient results. Each column represents a single patient grouped by the total number of autoreactive positive tests that the patient displayed. Bolded boxes represent clinical positive tests with the color indicating the magnitude of the test result. Scale for each test is documented below the heatmap. (b-c) Autoantibody titers from heathy donor (HD), acute mild/moderate (mild/mod) COVID-19, acute severe/critical (sev/crit) COVID-19, or PASC patient groups. Red line indicates clinical positive test threshold. (b) Anti-RNA polymerase III (RNA Pol III) titers. (c) Anti-double stranded DNA (dsDNA) titers. (d) Frequency of the total number of positive autoantigen tests from indicated patient groups. 
a

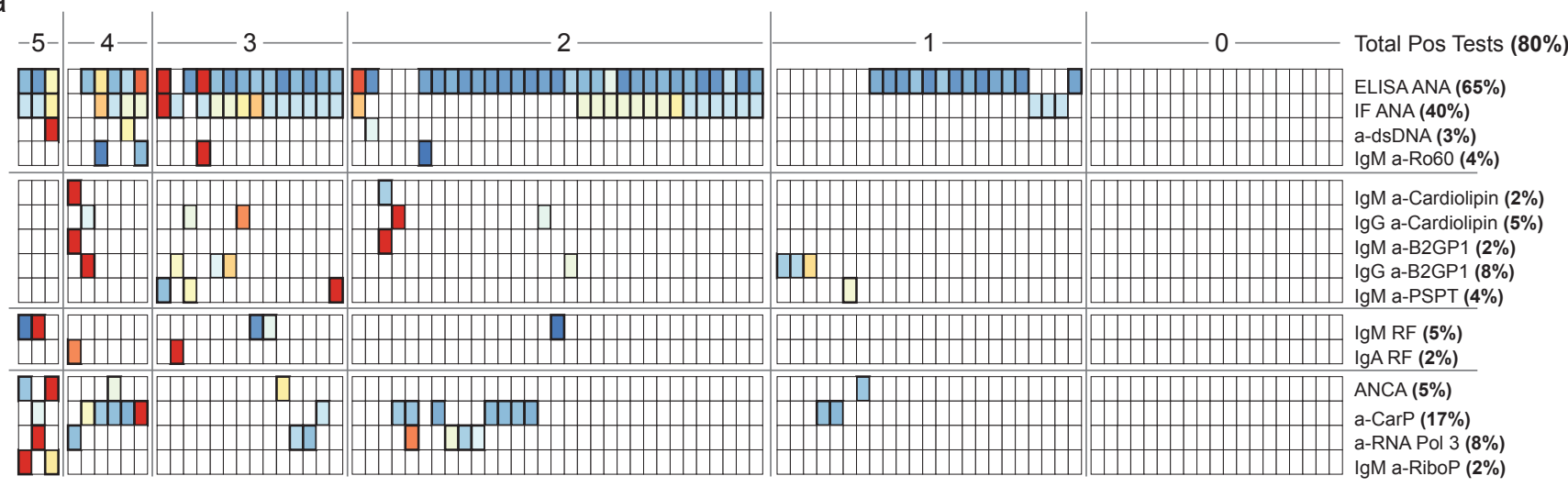

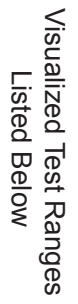
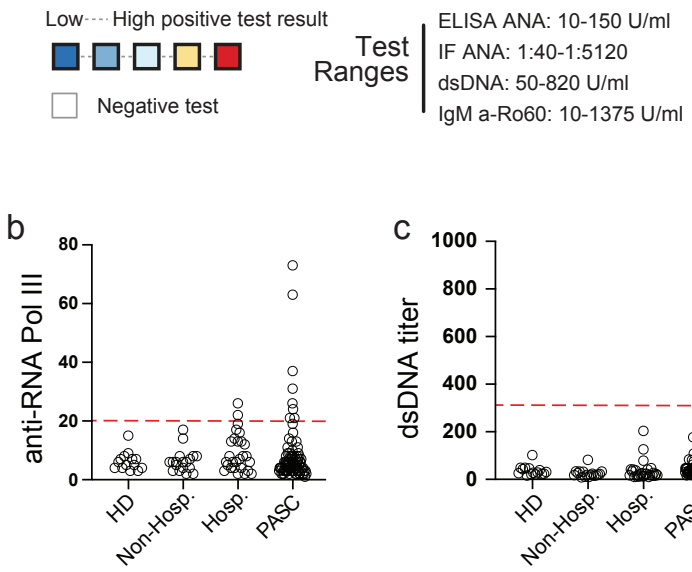

IgM a-Cardiolipin: 10-115 U/ml IgG a-Cardiolipin: 10-42.9 U/ml IgM a-B2GP1: 10-42 U/ml IgG a-B2GP1: 10-96.7 U/ml IgM a-PSPT: 10-150 U/ml
IgM RF: 5-91 U/ml IgA RF: $10-28 \mathrm{U} / \mathrm{ml}$ a-CarP: 10-89 U/ml a-RNA Pol 3: 10-73 U/ml IgM a-RiboP: 10-28 U/ml

d

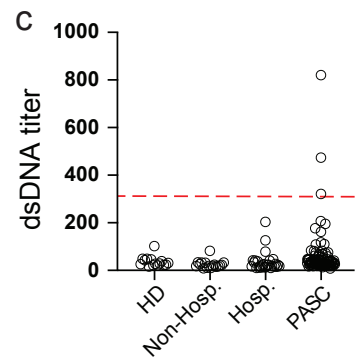

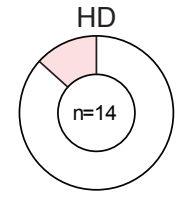
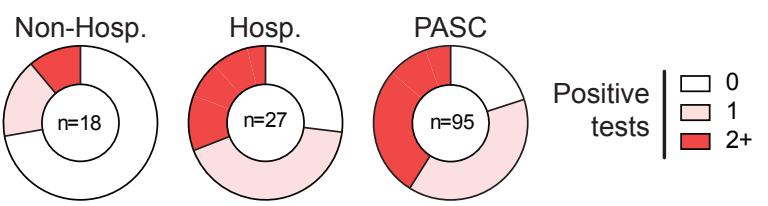
medRxiv preprint doi: https://doi.org/10.1101/2021.09.21.21263845; this version posted September 26,2021 . The copyright holder for this preprint (which was not certified by peer review) is the author/funder, who has granted medRxiv a license to display the preprint in perpetuity.

All rights reserved. No reuse allowed without permission.

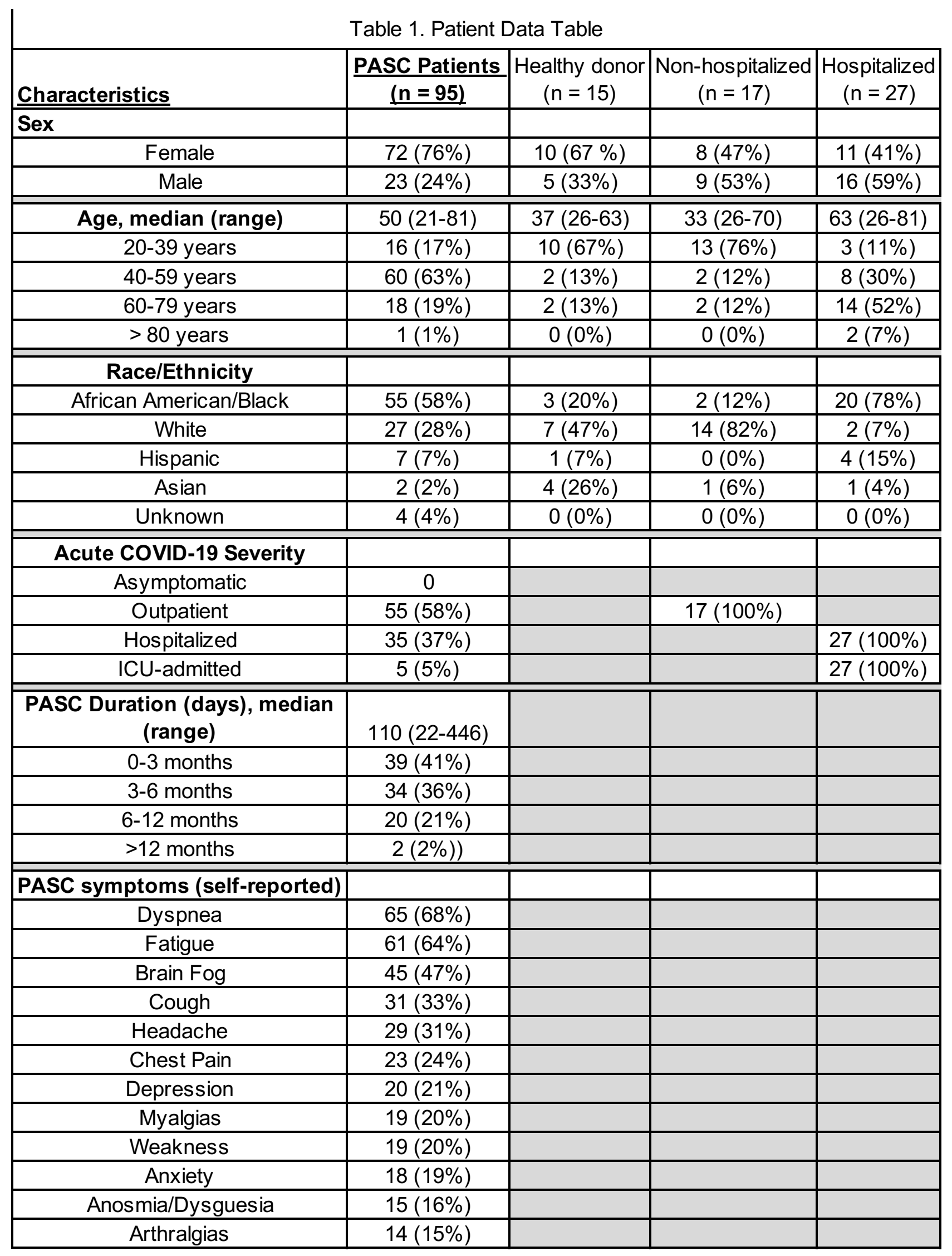

